\title{
Valor justo da Tractebel Energia: uma avaliação a partir dos principais modelos de precificação de ativos
}

\author{
Renato Campos ${ }^{1}$ \\ Juliana Tatiane Vital ${ }^{2}$ \\ Gilberto de Oliveira Moritz ${ }^{3}$ \\ Alexandre Marino Costa $a^{4}$
}

\section{Resumo}

O presente estudo teve como objetivo definir o atual valor justo da Tractebel Energia, a partir dos principais modelos de precificação de ativos. A empresa objeto foi tomada como base em função de seu crescimento estável e da facilidade de se obter dados, uma vez que é sediada na cidade de Florianópolis. Não obstante, a volatilidade com que suas ações têm sido precificadas despertou interesse. Com isso, este estudo pretendeu fornecer subsídio para a tomada de decisão de investidores, no que diz respeito à compra ou venda das ações da empresa. Para tanto, a fundamentação teórica tratou sobre o conceito de avaliação de ativos e dos principais modelos disponíveis, ressaltando suas aplicações e limitações, os quais são: avaliação contábil, relativa, modelo de dividendo descontado e fluxo de caixa descontado. No que tange ao aspecto metodológico, a pesquisa se enquadra em exploratória, descritiva, eminentemente quantitativa, estudo de campo e de caso. Além disso, fez-se uso de investigação documental, bibliográfica, entrevista e do programa Economática. Com isso, a análise de dados procurou inicialmente levantar as premissas demandadas por cada um dos modelos analisados e aplicá-los. Os resultados obtidos foram então comparados entre si e ajustados, para que houvesse uma coerência. Posteriormente, foi adotada uma média aritmética para se atribuir um valor justo à empresa. A partir dessas média definiu-se um intervalo de aceitação, em função da variabilidade dos resultados e da incerteza nas estimativas.

Palavras-chave: Valuation. Dividendo descontado. Fluxo de caixa descontado.

\footnotetext{
${ }^{1}$ Graduado em Administração. Endereço: Universidade Federal de Santa Catarina, Campus Reitor João David Ferreira Lima, Bairro Trindade -Florianópolis, SC-Brasil -CEP88.040-970.E-mail: racampos85@hotmail.com.

${ }^{2}$ Doutoranda em Administração. Professora do Departamento de Ciências da Administração da Universidade Federal de Santa Catarina. Endereço: Universidade Federal de Santa Catarina, Campus Reitor João David Ferreira Lima, Bairro Trindade - Florianópolis, SC - Brasil CEP88.040-970.E-mail: julianatvital@yahoo.com.br.

${ }^{3}$ Doutor em Engenharia de Produção. Professor do Departamento de Ciências da Administração da Universidade Federal de Santa Catarina. Endereço: Universidade Federal de Santa Catarina, Campus Reitor João David Ferreira Lima, Bairro Trindade - Florianópolis, SC - Brasil CEP88.040-970.E-mail: gomoritz@cse.ufsc.br.

${ }^{4}$ Doutor em Engenharia de Produção. Professor do Departamento de Ciências da Administração da Universidade Federal de Santa Catarina. Endereço: Universidade Federal de Santa Catarina, Campus Reitor João David Ferreira Lima, Bairro Trindade - Florianópolis, SC - Brasil CEP 88040-970.E-mail: marino@cse.ufsc.br. Artigo recebido em: 03/01/2010. Aceito em: 23/04/2010. Membro do Corpo Editorial Científico responsável pelo processo editorial: Martinho Isnard Ribeiro de Almeida.
} 


\section{Introdução}

A economia brasileira passou por uma enorme estabilidade e expansão durante o período de 2002 a 2008, que se refletiu principalmente no mercado financeiro. Contudo, essa prosperidade foi interrompida em março de 2008 com o início da crise econômico-financeira que, dentre outras consequências, provocou uma forte queda do mercado acionário. Essa queda se deu de diferentes formas nas empresas brasileiras. Mesmo as empresas que não dependem tanto das condições econômicas, como as de utilidade pública, foram muito penalizadas. Com isso, verificou-se uma aparente distorção no preço de algumas ações, como as da Tractebel, pertencente ao setor de energia elétrica.

A aparente distorção, causada pela mudança nas condições econômicas, pode ser parcialmente justificada em função do ambiente de incerteza, restrição do crédito, enfraquecimento da demanda e aumento do risco. Por outro lado, diante da falta de informações e do pânico, investidores tendem a tomar decisões demasiadamente irracionais e subprecificar ativos, gerando assim grandes oportunidades de investimento. Em função disso, cabe apresentar e distinguir dois conceitos fundamentais: preço $e$ valor. O primeiro deles, de acordo com Pinheiro (2008), está relacionado ao valor de mercado de uma empresa, que é cotado diariamente na bolsa de valores. Já o segundo reflete o "preço justo" (ou valor intrínseco), ou seja, quanto um ativo deveria efetivamente valer, em função de seus fundamentos e perspectivas futuras.

A partir do exposto, este estudo espera fornecer subsidios para a tomada de decisão de investidores e da própria organização. Sabe-se que uma das características do mercado acionário é a volatilidade, no entanto Cavalcanti, Misume e Rudge (2005) afirmam que, de acordo com a hipótese de mercados eficientes, no longo prazo o preço de uma ação tende a refletir seu valor intrínseco. Assim, o objetivo geral deste estudo é definir o atual valor justo da empresa Tractebel, a partir dos principais modelos de precificação de ativos. 


\section{A Avaliação de Empresas}

Os termos avaliação e valoração provêm do inglês valuation e estão associados ao processo de atribuir valor, ou um preço justo, a determinado ativo. Nesse sentido, Damodaran (2002) ressalta que o valor de uma empresa depende da sua capacidade de gerar fluxos de caixa e das incertezas associadas a esses fluxos. Ainda nessa linha, Nogueira (1999) aponta que a avaliação de empresas, diferente da avaliação de obras, não deve se basear em percepções, mas no profundo conhecimento da organização e do mercado em que ela atua. Cornell (apud CRUZ, 2007) salienta também que valor é o preço em que uma propriedade trocaria de mãos, entre comprador $e$ vendedor, estando ambos dispostos a fazer a transação.

Quanto à importância, Nogueira (1999) ressalta que a avaliação é útil na tomada de decisões de investimentos, na análise de fusões e aquisições, nas aberturas de capital, nas privatizações e nas recompras de ações. Damodaran (2002) relaciona também o impacto das decisões estratégicas, financeiras e operacionais, na maximização do valor aos acionistas. Nesse sentido, a avaliação pode funcionar como uma forma de feedback aos proprietários, em relação à gestão e eficiência da administração de seus negócios.

Um ponto interessante levantado por Damodaran (2007) é o fato de que há duas visões sobre o processo de avaliação. Enquanto alguns teóricos acreditam que a avaliação, quando bem feita, seja uma ciência exata, com pouca margem para opinião, outros a consideram uma forma de arte, em que analistas perspicazes podem manipular os números de modo a gerar o resultado desejado. Segundo Damodaran (2007), existe um meio termo, e, em função disso, três elementos devem ser considerados: os vieses que os analistas trazem ao processo, a incerteza com que têm que lidar e a complexidade que as informações e os modelos trazem à avaliação.

A respeito dos métodos de avaliação utilizados, vale mencionar que não existe uniformização, ou seja, cada autor aborda aquele que considera mais eficiente e com maior aceitação. Diante disso, Cornell (apud CRUZ, 2007) identifica quatro modelos: a avaliação contábil; a avaliação de ações e dívidas; a avaliação relativa; e a avaliação pelo fluxo de caixa descontado. Já Copeland, Koller e Murrin (2002) focam seus trabalhos na avaliação pelo método do fluxo de caixa descontado, mas enumeram também o lucro por ação, o retorno sobre o patrimônio líquido e o valor de mercado adicionado. Damodaran (2002), por sua vez, adota os mesmos métodos de Cornell, 
acrescentando o modelo de opções reais, que é utilizado principalmente por empresas de alta tecnologia. Já Ross, Westerfield e Jaffe (2008) e Neiva (1999), além dos métodos listados por Cornell, utilizam também o modelo de dividendo descontado.

\subsection{Avaliação Contábil}

A forma mais simples de se avaliar uma empresa, seja de capital fechado ou aberto, é através da avaliação contábil, ou por valor de livro ajustado. Essa metodologia, segundo Cornell (apud CRUZ, 2007) está baseada no balanço patrimonial e consiste em somar os valores exigidos pelos investidores, o que pode ser feito de duas formas. A primeira seria somar os itens do patrimônio líquido (como capital social, reservas e lucros acumulados) aos itens não operacionais do passivo (como dívidas de curto e longo prazo). A outra forma seria simplesmente diminuir do ativo os passivos operacionais. Nesse cálculo, os passivos operacionais (contas a pagar e crédito de fornecedores) não são considerados, pois não são onerosos, sendo tratados como capital de giro não monetário.

Um aspecto importante em qualquer modelo de avaliação, segundo Cornell (apud CRUZ, 2007), é a distinção entre avaliação empresarial e patrimonial. Assim, como a primeira representa o valor do negócio todo e inclui todas as fontes de financiamento, a outra se limita ao valor dos acionistas. Portanto, o valor contábil apresentado anteriormente retrata o valor de toda a organização. A partir dele, pode-se chegar ao valor patrimonial, ou do acionista, excluindo as dívidas não operacionais de curto e longo prazo, ou seja, incluindo-se apenas o patrimônio líquido.

Em função da simplicidade e facilidade em se calcular o valor contábil, tal método apresenta diversas limitações. A principal delas, apontada por Martins (2001), reside no fato de que os valores constantes no balanço patrimonial nem sempre refletem os valores de mercado, uma vez que aqueles se baseiam em custos históricos e não consideram a inflação. Outro ponto é a falta do "capital organizacional" no balanço, que é um dos ativos mais importantes e compreende o relacionamento da organização com seus colaboradores, fornecedores e clientes, tendo assim, impacto direto nos resultados do negócio. 
Ainda no que tange às limitações do valor contábil, Falcini (1995, p. 18) explana que apesar desse custo ser "perfeitamente conhecido, no momento da compra, em que representa efetivamente seu valor econômico, à medida que o tempo passa, aquele custo vai se tornando cada vez mais irrelevante para a determinação do valor econômico". Tal diferença, segundo o autor, pode ser justificada não só pela depreciação do uso, como também pelo progresso tecnológico, pelas condições variáveis de mercado e pelo valor da moeda. Dessa forma, uma alternativa mencionada por Neiva (1999) para minimizar tais limitações seria a adoção da avaliação patrimonial de mercado, que consiste em mensurar o conjunto de ativos e passivos exigíveis a partir do valor de mercado de seus itens. Porém, assim como a avaliação tradicional, essa metodologia não contempla a capacidade do negócio em gerar resultados.

\subsection{Avaliação Relativa}

Outra forma de se avaliar uma empresa é a avaliação relativa ou por múltiplos. Segundo Damodaran (2002), essa forma está baseada no princípio da teoria econômica quando afirma que empresas semelhantes deveriam possuir preços semelhantes. Nesse sentido, o valor de um ativo pode ser obtido a partir de múltiplos de preços de ativos com características similares. Para tanto, faz-se necessário selecionar um indicador de referência (como o lucro, o valor patrimonial ou as vendas) de empresas comparáveis, dividi-lo pelo valor de mercado de tais empresas e multiplicar o dado encontrado pelo indicador de referência da empresa objeto.

$$
V_{\text {alvo }}=X_{\text {alvo }} * \frac{V_{\text {comparável }}}{X_{\text {comparável }}}
$$

Onde:

$V_{\text {alvo }}$ é o valor da empresa alvo;

$X_{\text {alvo }}$ é a variável utilizada, por exemplo o lucro;

$V_{\text {comparável }}$ é valor da empresa comparável;

$X_{\text {comparável }}$ é variável da empresa comparável.

Pinheiro (2008) afirma que essa metodologia não procura calcular o valor absoluto de uma empresa, apenas comparar se determinado ativo está 
subvalorizado ou supervalorizado em termos relativos. Em função disso, podese considerar também uma comparação com os valores históricos da empresa. Nessa mesma linha, Damodaran (2007) argumenta que diferente do fluxo de caixa e do dividendo descontado, tratados a seguir, que procuram o valor intrínseco, a avaliação relativa desiste de estimar o valor e deposita sua fé na ideia de que o mercado possui o valor correto, pelo menos na média.

A principal vantagem, apontada por Ross, Westerfield e Jaffe (2008), sobre esse modelo, é a sua facilidade, ou seja, pode-se determinar o valor de uma empresa com um pequeno número de parâmetros. Outra vantagem é o tempo de cálculo, que permite atribuir um novo valor ao ativo de forma quase instantânea quando há mudanças no preço, no lucro ou em qualquer outra variável. Além disso, essa metodologia é particularmente útil e gera resultados interessantes, quando um grande número de empresas comparáveis está sendo negociada e o mercado está, na média, precificando corretamente.

Em relação às desvantagens, os autores identificam a dificuldade de encontrar uma empresa com características semelhantes ao ativo objeto, em termos de porte, estrutura patrimonial e risco. Em função disso, na prática, geralmente se assume o significado de empresas que estão no mesmo ramo de atuação que o ativo objeto. Outra desvantagem seria a não consideração das condições de mercado, visto que ele pode estar sub ou supervalorizado em determinados momentos. Pode-se mencionar ainda questões contábeis e fatos isolados que podem distorcer as informações geradas. Todos esses aspectos podem fazer com que os múltiplos se sujeitem ao mau uso e à manipulação.

Os principais múltiplos identificados por Pinheiro (2008) são:

a) Price Earning Ratio (PER) ou Preço Lucro (P/L): faz uma relação entre o preço de mercado e o lucro da empresa, relacionando de uma forma simples, o número de anos que um acionista terá de esperar para recuperar o seu capital. Quanto mais alto o índice, mais "cara" é a empresa;

b) Price EBITDA (P/EBITDA): é bastante semelhante ao $\mathrm{P} /$ L em cálculo e utilização, mas relaciona o valor de mercado ao lucro antes do juros, impostos, depreciação e amortização. Sua diferença reside no fato desse indicador demonstrar a capacidade da organização em gerar resultados, uma vez que o lucro pode apresentar valores distorcidos, em função de ajustes contábeis. Sua análise é semelhante ao P/L; 
c) Preço/Valor Patrimonial Ajustado (P/VPA): estabelece uma comparação entre o valor de mercado e o valor contábil. Esse indicador, diferente dos outros dois, não considera o efeito de rentabilidade, mas permite conhecer o goodwill que o mercado oferece pela empresa. Sua análise é semelhante aos outros, ou seja, quanto mais alto, mais cara é a empresa;

d) Dividend Yield (DY): representa a rentabilidade dos acionistas em determinado ano. É obtido a partir da divisão entre os dividendos e o preço por ação. Quanto mais alto o indicador, maior a rentabilidade e melhor será para o acionista.

O PER e do P/VPA, citados por Pinheiro (2008) e Damodaran (2002), relaciona também o múltiplo de receitas (PSR), que compara o preço por ação com a receita líquida. Assim como o P/EBTIDA não é tão afetado pelos princípios contábeis e indicar a capacidade de vendas de uma organização, sendo que, quanto mais baixo for, melhor será.

\subsection{Modelo de Dividendo Descontado}

Tal modelo, segundo Neiva (1999), baseia-se na ideia de que o valor de uma empresa depende do fluxo de dividendos futuros e da taxa de desconto utilizada para trazer esse fluxo ao valor presente. Nesse sentido, os dois inputs básicos do modelo são: dividendos esperados e taxa de retorno exigida pelos acionistas. Assim, como os dividendos podem ser obtidos em função das taxas de crescimento esperadas para os lucros, e as razões de payout (parcela do lucro distribuída aos acionista); a taxa de retorno, depende do grau de risco dos fluxos futuros e é mensurada de diferentes formas através de diversos modelos.

Ross, Westerfield e Jaffe (2008) salientam que os únicos fluxos de caixa de um acionista são os dividendos distribuídos e o preço de venda ao se desfazer de uma ação. Porém, tendo em vista que o último fluxo é obtido em função dos dividendos que serão recebidos após a data da venda, conclui-se que o valor de uma empresa é igual ao valor presente dos dividendos futuros esperados. Com isso, os autores apontam que, quando os investidores não possuem condições de assumir o controle de uma companhia, a utilização do modelo de dividendos (MDD) é mais adequada do que o fluxo de caixa 
descontado, que será abordado posteriormente. O MDD é expresso pela seguinte equação:

$$
P_{\mathrm{o}}=\sum \frac{d i v}{(1+k)^{t}}
$$

Onde:

$P$ é o valor presente da empresa;

Div é o dividendo pago aos acionistas; $e$

$K$ é a taxa de retorno exigida.

Para estimar as taxas de crescimento e, consequentemente, os dividendos futuros, Ross, Westerfield e Jaffe (2008) afirmam que deve-se relacionar o índice de retenção do lucro à taxa de retorno. $O$ primeiro é obtido a partir do payout que, como descrito anteriormente, representa a parcela do lucro distribuída aos acionistas. Já a taxa de retorno, os autores apontam que pode-se supor que os projetos selecionados no ano corrente tenham retorno esperado igual aos projetos de outros anos. Com isso, recomenda-se a utilização do retorno sobre o patrimônio líquido $(\mathrm{ROE})$, medido em termos históricos.

$$
g=\text { índice de retenção * retorno sobre o patrimônio líquido }
$$

No que tange à taxa de desconto $(\mathrm{k})$, apesar da existência de diversos métodos, há um consenso por parte dos teóricos sobre a utilização e aceitação do CAPM (Capital Asset Princing Model), uma vez que esse modelo considera a taxa livre de risco, o prêmio de mercado e o grau de sensibilidade de um ativo em relação às variações de mercado. Esse método e seus componentes serão tratados com maiores detalhes na seção 2.4.3.

Sobre os pontos fortes do MDD, Neiva (1999) expõe inicialmente a sua simplicidade e lógica intuitiva. Afinal, os dividendos representam o único fluxo de caixa da empresa que é tangível aos investidores. Além disso, há necessidade de se obter menos premissas para a previsão de dividendos do que a previsão do fluxo de caixa livre. Por fim, pode-se argumentar que os gerentes ajustam os dividendos em níveis que possam sustentar, mesmo com lucros voláteis. No que tange aos pontos fracos, o autor chama a atenção para o fato de que muitas empresas optam por reter o caixa que poderiam distribuir aos acionistas. Assim, embora os investidores possam não ter direito explícito aos saldos de caixa, eles efetivamente possuem uma parcela deles através do patrimônio líquido. 


\subsection{Modelo de Fluxo de Caixa Descontado}

O modelo de fluxo de caixa descontado (FCD) é o método mais reconhecido e utilizado por analistas e acadêmicos na avaliação de empresas, visto que considera toda a complexidade macroeconômica e organizacional, e pode ser empregado em praticamente qualquer ativo. Suas premissas são semelhantes ao modelo de dividendo descontado, já que também partem da ideia de que o preço justo corresponde ao fluxo de resultados futuros descontados no valor presente. No entanto, diferente da outra metodologia, esta utiliza o fluxo de caixa livre e não os dividendos.

Copeland, Koller e Murrin (2002, p. 136) afirmam que

[...] o modelo FCD determina o valor acionário de uma empresa como sendo o valor de suas operações menos o valor do endividamento e outras formas de passivo de prioridade superior à do capital ordinário.

Já Damodaran (1997) salienta que esse método procura determinar o valor de um negócio a partir de sua capacidade de remunerar seus proprietários no longo prazo. Ainda nessa linha, Martins (2001) aponta que o FCD é o modelo que revela a efetiva capacidade de geração de riqueza de um empreendimento, uma vez que utiliza o fluxo de caixa e não o lucro contábil.

Em relação a suas vantagens, Copeland, Koller e Murrin (2002) afirmam que o FCD permite a avaliação plena da empresa, leva em consideração perspectivas de longo prazo e propicia a análise da sensibilidade às mudanças nas variáveis. Por outro lado, sua maior desvantagem está relacionada à grande complexidade na projeção de dados, já que pequenas alterações provocam grande distorção nos valores finais.

Nesse método, para determinar o preço justo de um ativo, deve-se estabelecer seus fluxos de caixas futuros e uma taxa de desconto que trará tais fluxos no valor presente, conforme a fórmula a seguir:

$$
P_{\mathrm{o}}=\sum \frac{f c}{(1+k)^{t}}
$$

Onde:

$P$ é o valor prestente da empresa;

Fc é o fluxo de caixa gerado no tempo; e $K$ é a taxa de retorno exigida. 
Cornell (apud CERBASI, 2003) descreve sucintamente os três elementos fundamentais na determinação do FCD da seguinte forma:

a) fluxo de caixa: corresponde aos recursos obtidos através das operações e que ficam à disposição dos acionistas ou da empresa. É obtido a partir de variáveis como vendas, margens, estrutura de custo e investimentos;

b) taxa de desconto: é utilizada para obter o valor presente dos fluxos futuros e pode ser determinada a partir do custo médio ponderado de capital, que leva em consideração o custo dos acionistas e o custo de capital de terceiros;

c) valor residual ou da perpetuidade: corresponde ao valor que os acionistas esperam receber por suas ações ao final de uma data, ou então, o valor do fluxo perpétuo, assumindo um estado de equilíbrio a partir do final do período analisado.

\subsection{Crescimento esperado}

Ao projetar fluxos de caixa, os analistas deparam-se com a incerteza de uma forma mais direta. A partir disso, Damodaran (2007) apresenta três formas genéricas de estimar o crescimento. A mais simples consiste em analisar o passado da empresa e utilizar a taxa de crescimento histórica divulgada por ela. O perigo dessa abordagem é que o crescimento passado pode fornecer poucos indícios sobre o crescimento futuro. Uma outra forma, não muito confiável, é obter estimativas de fontes mais informadas, como a administração da empresa, ou outros analistas.

Em ambos os casos, o autor ressalta que o crescimento se torna uma variável exógena que afeta o valor. Em função disso, a forma mais saudável de incorporá-lo é tornando-o endógeno, ou seja, transformá-lo em uma função de quanto uma empresa reinveste em seu crescimento e a qualidade desse investimento. Essa forma foi apresentada no modelo de dividendo descontado, ao se relacionar a taxa de retenção ao retorno sobre o patrimônio próprio. Contudo, ao se analisar fluxo de caixa, e não dividendos, é preciso levar em consideração um indicador de investimento que transcenda o lucro líquido.

$$
g=\text { taxa de reinvestimento total } * \text { retorno sobre o ativo total }
$$




\subsubsection{O valor residual ou da perpetuidade}

Uma outra dificuldade encontrada na utilização do fluxo de caixa descontado é estimar o valor residual, ou de liquidação, ou seja, o valor que poderia ser obtido por uma empresa ao final de suas operações. Tal dificuldade, segundo Damodaran (1997), está relacionada ao fato da maior parte das organizações não possuírem um prazo de extinção determinado. Além disso, não é possível trazer todos os fluxos de caixa a valores presentes com um nível considerável de precisão.

Diante disso, Cornell (apud CERBASI, 2003) aponta que o analista deve projetar fluxos de caixa por um período suficientemente longo (entre cinco $e$ dez anos) até que eles se estabilizem. Após esse horizonte, deve-se assumir uma taxa de crescimento constante, à qual normalmente corresponde a taxa de crescimento da economia. Nesse sentido, percebe-se que valor residual nada mais é do que o fluxo de caixa descontado a partir do final do período de projeção e para que possa ser incorporado ao valor da empresa, também deve ser trazido a valor presente.

\subsubsection{A taxa de desconto}

A taxa de desconto utilizada para trazer os fluxo de caixa e o valor residual a valores presentes deve, segundo Martins (2001), refletir o custo de oportunidade de cada fonte de recurso. Portanto, como há utilização de fontes próprias e de terceiros, normalmente se emprega o custo médio ponderado de capital (WACC) que consiste em ponderar a participação de cada fonte de recurso sobre o total e multiplicar pelo seu custo, conforme a fórmula:

$$
W A C C=\left(\frac{E}{\mathrm{E}+B}\right) * k_{e}+\left(\frac{\mid B}{\mathrm{E}+B}\right) * k_{b} *\left(1-T_{c}\right)
$$

Onde:

E é o montante de capital próprio;

$B$ é o montante de capital de terceiros;

$K_{e}$ é o custo de capital próprio;

$K_{b}$ é o custo de capital de terceiros; $e$

$T_{c}$ é a alíquota do imposto de renda. 
A identificação do custo de capital de terceiros não exige muita dificuldade e pode ser obtida de maneira bastante objetiva, dividindo-se as despesas financeiras pelo total das dívidas. Por outro lado, o cálculo do custo de capital próprio é bastante complexo, haja vista que o retorno exigido pelos acionistas muda em função de alterações econômicas e da própria empresa. Diante disso, este custo deve corresponder à remuneração mínima exigida pelos acionistas para manterem seus recursos aplicados na empresa.

Existem diversos modelos para se calcular o custo de capital próprio. No entanto, Copeland, Koller e Murrin (2002), Damodaran (1997), Martins (2001) e Cornell (apud CERBASI, 2003) reconhecem o CAPM como o modelo mais apropriado. O CAPM foi desenvolvido por Sharpe em 1970 e possui a vantagem de ser fácil, intuitivo e simples. De acordo com Damodaran (1997), esse método parte do pressuposto de que o risco de um ativo pode ser dividido entre uma parcela que depende do mercado como um todo (risco sistêmico) e outra, que depende apenas da empresa e suas operações (risco específico). No entanto, tendo em vista que o risco específico pode ser evitado mediante a diversificação, somente o risco sistêmico deve ser recompensado. Assim, no CAPM, o custo de oportunidade é obtido através do retorno da taxa livre de risco, mais o risco sistemático (Beta) multiplicado pelo prêmio de risco do mercado, conforme fórmula abaixo:

$$
K e=R_{f}+\beta\left(R_{m}-R_{f}\right)
$$

Onde:

Ke é o custo de capital próprio;

$R_{f}$ é a taxa de retorno livre de risco;

$R_{m}$ é a taxa de retorno do mercado;

$R_{m}-R_{f}$ é o prêmio pelo risco; $e$

$\beta$ é o risco sistêmico inerente à empresa.

Dos elementos contidos na fórmula desenvolvida por Sharpe e Pacheco (2004) eles descrevem a taxa livre de risco como sendo a taxa de retorno obtida em um ativo que não apresenta risco de crédito. No caso brasileiro, adota-se comumente a taxa Selic, que representa a remuneração do principal título da dívida pública em moeda nacional. A taxa de retorno do mercado, que o autor afirma ser a taxa de retorno esperada sobre o índice de mercado, no caso brasileiro, é representada pelo Índice Bovespa (Ibovespa). 
O terceiro elemento, o prêmio pelo risco, representa a diferença entre a taxa de retorno do mercado e a taxa de retorno livre de risco e reflete quanto um investidor espera receber pelo risco assumido. Por fim, o Beta é o coeficiente de risco específico de uma empresa com relação ao índice de mercado e mede a tendência de variação de uma ação em relação ao mercado.

\section{Metodologia}

O presente estudo é classificado como aplicado, pois se trata de um caso prático e objetiva fornecer subsídios para a tomada de decisão de investidores e da própria organização. Sobre os objetivos, o estudo é descritivo, uma vez que descreve a realidade estudada para, posteriormente, atribuir um preço justo a ela. Em relação aos meios de investigação, o estudo é de caso, de campo, documental e bibliográfico. Por fim, no que tange à abordagem, a pesquisa é predominantemente quantitativa.

O objeto de estudo é a Tractebel, empresa sediada em Florianópolis, geradora de energia elétrica, que desde seu surgimento, em 1998, vem apresentando um crescimento sólido, constante e superior ao de seu setor. Durante a crise, empresas de utilidade pública, como a Tractebel, foram utilizadas como proteção contra as quedas e incertezas de mercado, em função de sua baixa volatilidade e pouca dependência em relação às condições econômicas. Mesmo assim, chama a atenção o fato de suas ações, que antes da crise estavam em $\mathrm{R} \$ 25,35$, atingirem $\mathrm{R} \$ 17,05$ e, em novembro de 2009, se encontrarem por volta de $\mathrm{R} \$ 22,00$.

No que tange à coleta de dados, utilizou-se as seguintes fontes de informação: livros bibliográficos, cartilhas e informativos elaborados pela própria empresa, a Internet, o programa Economática, entrevista informal com o gerente da área de relações com investidores e apresentação dos resultados da empresa, referente ao segundo semestre de 2009 , realizada no dia 15 de agosto de 2009.

$\mathrm{Na}$ análise dos dados, determinou-se o valor intrínseco da empresa Tractebel, segundo os principais modelos de precificação de ativos, de forma a fornecer subsídio para a tomada de decisão de investidores e da própria organização. Para tanto, foi necessário descrever inicialmente cada um dos modelos utilizados e ressaltar suas aplicações e limitações. Posteriormente, foi imprescindível caracterizar a empresa objeto, em termos de atividades 
desenvolvidas, peculiaridades, história, desempenho econômico-financeiro e aspectos gerais. Após essa etapa, houve a aplicação de cada um dos métodos estudados, o que implicou na definição e projeção de diversas premissas. A partir dessas premissas, houve a aplicação dos modelos, a comparação dos resultados alcançados e a definição de um preço-alvo para a Tractebel.

\section{Análise de Dados}

Com mais de uma década de atuação como empresa privada, a Tractebel Energia, sediada na cidade de Florianópolis, Estado de Santa Catarina, é responsável por cerca de $8 \%$ da geração de energia elétrica do Brasil, o que a torna líder do setor privado de geração e umas das líderes em negócios com clientes livres, para quem vende $35 \%$ de sua produção anual. A companhia pertence ao grupo franco-belga GDF SUEZ, que detêm $68,7 \%$ de seu controle, possui ações negociadas na Bovespa e participa desde 2005 do Novo Mercado (segmento destinado à negociação de empresas que se comprometem voluntariamente com práticas de governança corporativa). A Tractebel conta, atualmente, com 900 colaboradores e tem como maiores clientes as concessionárias de distribuição de energia e indústrias. Seu parque gerador, com 19 usinas hidrelétricas, termelétricas e eólicas, está espalhado por todas as regiões do Brasil.

A despeito da crise econômica mundial, vale destacar que, mesmo diante do cenário recessivo, as vendas físicas da companhia foram $1,3 \%$ superiores no segundo trimestre de 2009 , em relação ao mesmo período do ano passado e totalizaram 3.473 MW médios. No entanto, houve queda de consumo dos consumidores livres na ordem de $12 \%$, em função da relação entre produção industrial $e$ as condições econômicas. Outro ponto importante foi o aumento no preço médio bruto dos contratos de venda, que atingiram $\mathrm{R} \$ 121,57 / \mathrm{MWh}, 11 \%$ maior do que o do mesmo período do ano anterior. Esse aumento refletiu o reajuste nos contratos existentes, principalmente aqueles com os consumidores livres, e o maior preço médio dos novos contratos com distribuidoras. 


\subsection{Aplicação dos Métodos de Avaliação}

\section{I.I Avaliação contábil}

O primeiro modelo de avaliação a ser empregado é a avaliação contábil que, como descrito anteriormente, consiste em extrair informações do balanço patrimonial, e parte do pressuposto de que empresas com baixo goodwill deveriam ser cotadas a um preço próximo ao seu valor patrimonial. No caso da Tractebel Energia, esse valor é de $\mathrm{R} \$ 3.667 .939 .000$, ou $\mathrm{R} \$ 5,6193$ por ação (considerando um total de 652.742.000 ações). Tal valor aparenta estar muito abaixo do atual valor de mercado da empresa, que é de aproximadamente $\mathrm{R} \$ 20,50$ por ação, o que poderia indicar uma supervalorização do ativo.

Diante disso, Neiva (1999) sugere ser necessário efetuar ajustes para se minimizar essa diferença. A solução apresentada pelo autor é a avaliação patrimonial de mercado, que consiste em mensurar o conjunto de ativos e passivos exigíveis a partir do valor de mercado de seus itens. No entanto, essa possibilidade demandaria uma auditoria contábil complexa e longa, o que inviabilizaria o presente estudo. Uma outra alternativa é a análise da relação histórica entre valor de mercado e valor patrimonial (P/VPA). Tal relação pode ser visualizada no Gráfico 1:

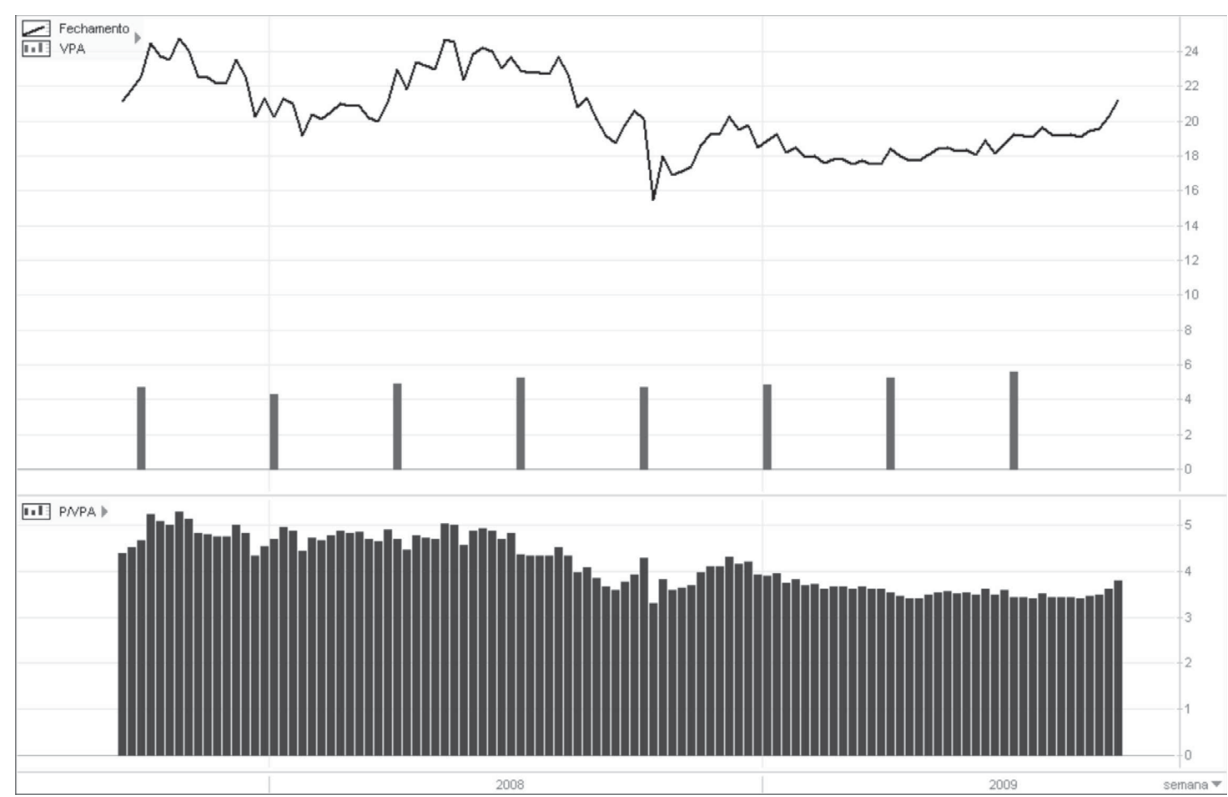

Gráfico 1: Variação no valor de mercado, no valor patrimonial e no P/VPA das ações da Tractebel Fonte: Economática (2010) 
A relação histórica do P/VPA dos dois últimos anos procura atenuar os efeitos da crise financeira e da forte queda no preço das ações. Assim, percebe-se que a razão entre valor de mercado e valor patrimonial, que atualmente é de aproximadamente 3,6, se encontra abaixo da média dos dois últimos anos, que é de 4,16. Diante disso, se essa média for tomada como base e o valor patrimonial se mantiver em $\mathrm{R} \$ 5,62$, o preço justo por ação deveria ser $\mathrm{R} \$ 23,37$.

\subsubsection{Avaliação relativa}

A avaliação relativa parte do pressuposto de que o valor de um empresa pode ser obtido através da comparação de indicadores de mercado de ativos com características similares, em termos de fluxos de caixa, risco e potencial de crescimento. Essa comparação pode se dar, segundo Damodaran (2002), com um par de empresas semelhantes ou com a média do grupo de pares, em que considera-se aquelas que compõem o setor em que a organizaçãoalvo atua. Diante disso, faz-se necessário identificar primeiramente as empresas comparáveis e os indicadores de referência, os quais são apresentados na Tabela 1:

Tabela 1: PER, P/EBITDA, P/VPA, DIV YLD e PSR do setor elétrico

\begin{tabular}{|c|c|c|c|c|c|c|}
\hline NOME & CLASSE & PER & P/EBITDA & P/VPA & DIV YLD & PSR \\
\hline Celesc & PNB & 11.80 & 3.50 & 0.80 & 5.70 & 0.40 \\
\hline Cemig & PN & 10.20 & 4.40 & 1.70 & 5.60 & 1.60 \\
\hline Copel & PNB & 8.00 & 4.70 & 1.00 & 3.30 & 1.50 \\
\hline CPFL Energia & ON & 12.40 & 5.60 & 3.10 & 7.60 & 1.60 \\
\hline Elektro & PN & 7.00 & 4.50 & 3.10 & 14.10 & 1.30 \\
\hline Eletrobras & ON & 10.20 & 6.90 & 0.40 & 5.40 & 1.20 \\
\hline Energias BR & ON & 7.30 & 3.10 & 1.00 & 6.00 & 0.90 \\
\hline Equatorial & ON & 6.70 & 2.50 & 1.70 & 14.70 & 0.80 \\
\hline Ger Paranap & PN & 13.20 & 5.10 & 1.20 & 5.80 & 3.50 \\
\hline Light S/A & ON & 6.70 & 3.50 & 1.70 & 16.40 & 0.90 \\
\hline Terna Part & UNT & 15.40 & 5.80 & 2.10 & 0.30 & 4.90 \\
\hline Tractebel & ON & 13.30 & 6.50 & 3.60 & 3.90 & 3.90 \\
\hline \multicolumn{2}{|c|}{ Média } & 10.18 & 4.68 & 1.78 & 7.40 & 1.88 \\
\hline
\end{tabular}

Fonte: Adaptado do Economática (2010)

Dada a dificuldade de se identificar pares semelhantes, foram selecionadas 12 empresas, dentre as 55 que compõem o setor elétrico 
brasileiro e que possuem ações negociadas em bolsa. Entre elas, estão: geradoras, transmissoras e distribuidoras de energia, de capital privado $e$ estatal. Para se aproximar das características da Tractebel foram consideradas apenas empresas que possuem PER, P/EBITDA, P/VPA, DY e PSR positivos. Não obstante, foi incluída apenas a ação de maior volume no último mês de cada empresa.

A partir da Tabela 1, levando em consideração o índice PER, que relaciona o preço ao lucro por ação, o preço teórico PER da empresa é de $\mathrm{R} \$ 15,62$ (10,18 PER setor * 1,5342 LPA Tractebel). Ao tomar como base o $\mathrm{P} / \mathrm{EBITDA}$, que divide o preço pelo lucro antes dos juros, impostos, depreciação e amortização, e é menos suscetível aos princípios contábeis, o preço P/EBITDA é $\mathrm{R} \$$ 14,66 (4,68 P/EBITDA setor * 3,1318 EBITDA Tractebel). Ao analisar o P/VPA, que relaciona preço e valor patrimonial, o resultado encontrado é $\mathrm{R} \$ 10,00$ (1,78 P/VPA setor * 5,6193 VPA Tractebel). Tomando o DY como referencia, que divide o dividendo por ação pelo preço, o valor passa a ser $\mathrm{R} \$ 10,85$ [(0,80278 div Tractebel / 7,4 YLD setor)*100]. $\mathrm{E}$, finalmente, ao considerar o PSR, preço dividido pela receita líquida, o preço teórico PSR se torna $\mathrm{R} \$$ 9,83 (1,88 PSR setor * 5,2277 vendas por ação Tractebel).

Diante da avaliação relativa setorial, pôde-se constatar que o valor intrínseco da Tractebel encontra-se em um intervalo entre $\mathrm{R} \$ 9,83$ e $\mathrm{R} \$ 15,62$; o que é bem inferior ao seu atual valor de mercado. Esse fato pode ser parcialmente justificado pelas altas taxas de crescimento que a empresa tem apresentado nos últimos anos e suas perspectivas futuras, que são superiores às de seu setor. Há de se considerar também que a maior parte das empresas comparadas são estatais e possuem um risco político adicional. Por fim, cabe ressaltar que a avaliação relativa não contempla as condições de mercado.

Diante disso, a diferença de preço entre a avaliação relativa e o atual valor da empresa pode ser minimizada através de uma análise histórica, que procura verificar o comportamento dos múltiplos ao longo do tempo e leva em consideração a relação deles com as condições de mercado. Esse tipo de análise compara a empresa com ela mesma e parte do pressuposto de que, apesar das oscilações e distorções de preço no curto prazo, no longo prazo as informações e perspectivas de um ativo tendem a ser refletidas em seu preço. A análise histórica contempla um horizonte de dois anos e procura identificar o padrão dos múltiplos ao longo do tempo. A análise do P/VPA foi realizada 
anteriormente e indicou que o valor médio do múltiplo se encontra em 4,16. Em função disso, o preço justo P/VPA médio do ativo é de $\mathrm{R} \$ 23,37$ (4,16 P/VPA médio histórico* 5,6193 VPA atual).

Sobre a análise do PER, o Gráfico 2 indica que apesar da recente recuperação frente à segunda metade de 2008, o PER ainda se encontra abaixo dos patamares de 2007. Porém, seu atual valor supera o valor médio dos últimos dois anos, que é 12,54. Com isso, o preço justo PER médio da Tractebel é de R\$19,24 (12,54 PER médio histórico * 1,5342 LPA atual).

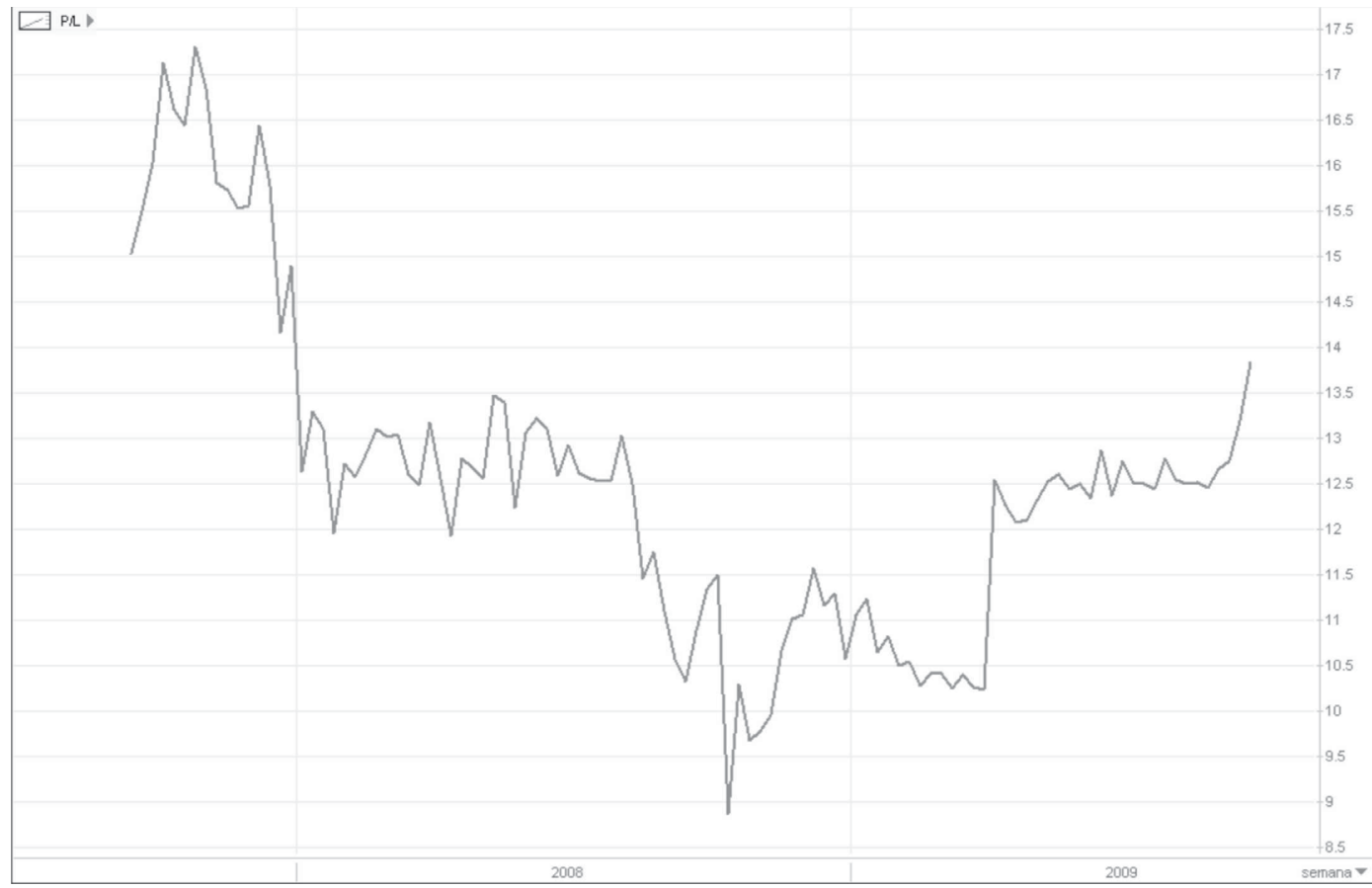

Gráfico 2: Variação do PER das ações da Tractebel de setembro de 2007 a setembro de 2009 Fonte: Economática (2010)

Em relação à análise histórica do P/EBITDA, mostrada no Gráfico 3, percebe-se o mesmo que o PER, ou seja, houve uma forte recuperação no último ano, mas o múltiplo ainda se encontra abaixo dos patamares de 2007. No entanto, diferente do PER, o valor P/EBITDA é inferior à média dos dois últimos anos, que é de 6,69. Assim, o preço justo P/EBITDA médio da Tractebel é de $\mathrm{R} \$ 20,95$ (6,69 P/EBITDA médio histórico * 3,1318 EBITDA atual). 


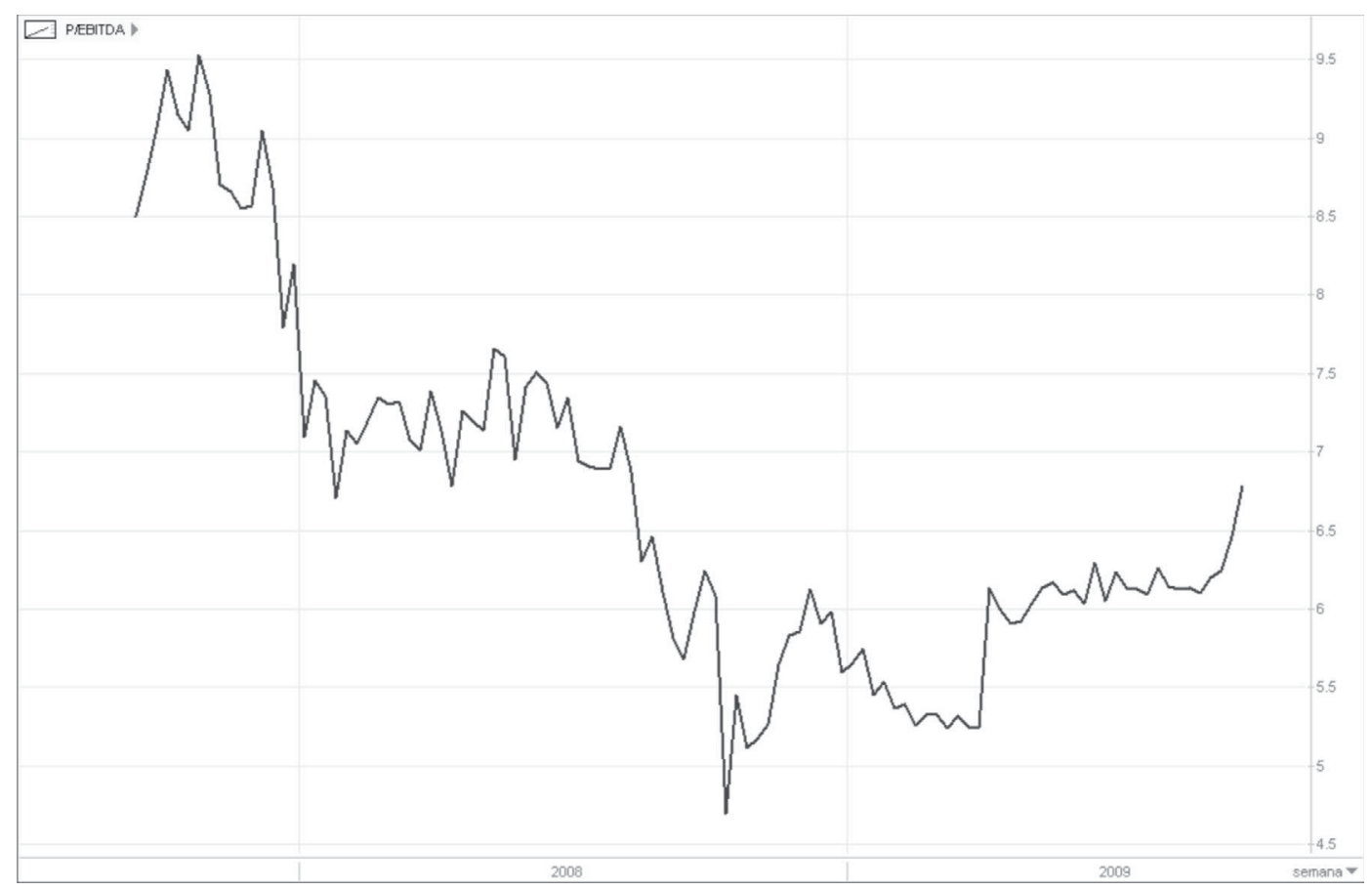

Gráfico 3: Variação do P/EBITDA das ações da Tractebel de setembro de 2007 a setembro de 2009

Fonte: Economática (2010)

No que tange ao DY, o Gráfico 4 indica que, ao contrário dos demais múltiplos, houve recuperação com o início da crise, uma vez que esse índice aumenta com a queda no preço das ações, mas atualmente há sinais de queda. Assim, seu valor médio é de 7,51 e seu preço justo é de $\mathrm{R} \$ 10,69$ [(0,80278 div atual / 7,51 YLD médio histórico)*100]. 


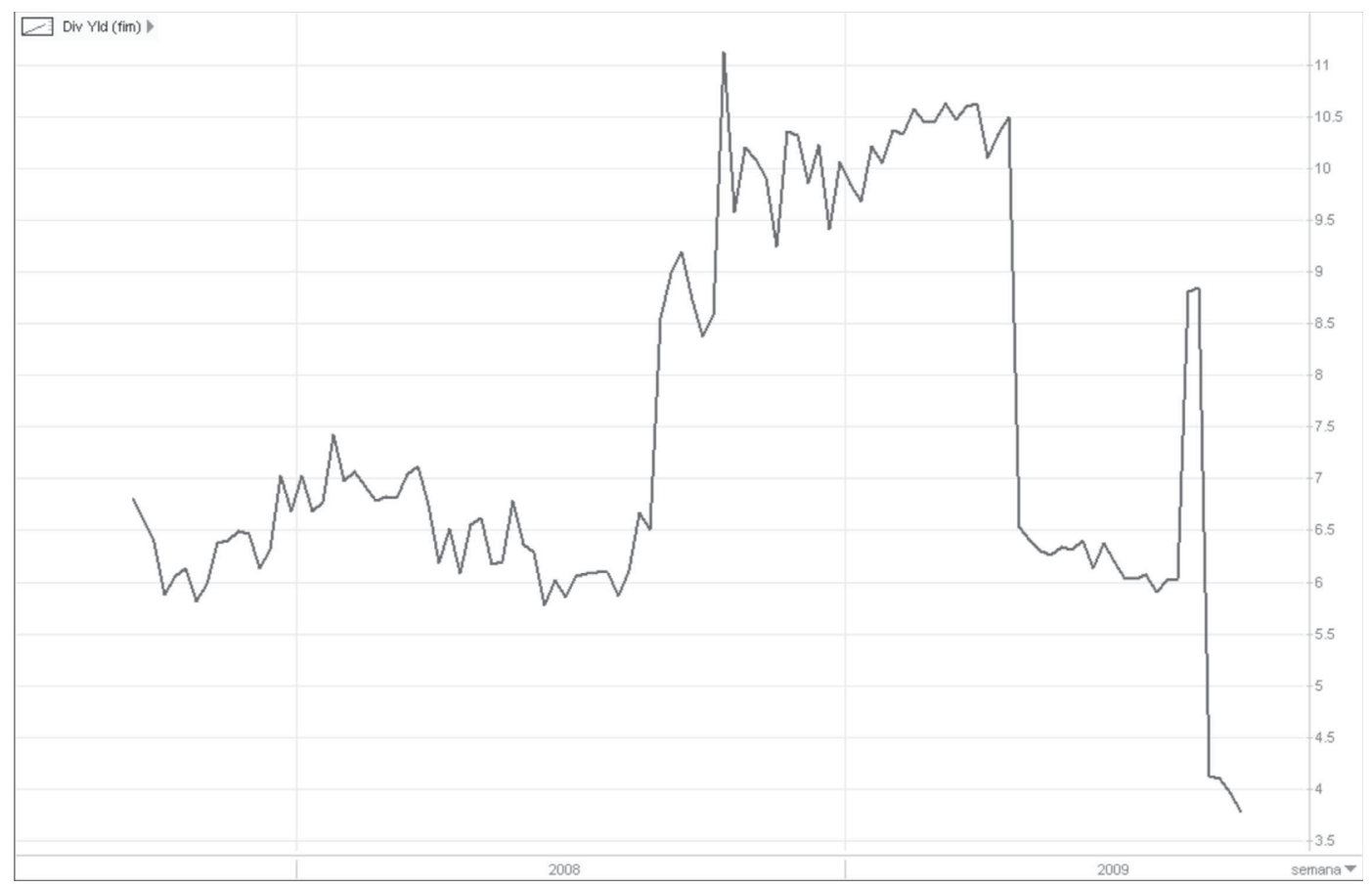

Gráfico 4: Variação do diviend yield das ações da Tractebel de setembro de 2007 a setembro de 2009

Fonte: Economática (2010)

Por fim, a análise do PSR, no Gráfico 5, mostra recuperação em relação ao último ano, porém o indicador ainda se encontra aquém de 2007. Seu valor médio dos últimos dois anos é de 4,09 e o preço justo calculado a partir dele é de $\mathrm{R} \$ 21,83$ (4,09 PSR médio histórico * 5,2277 vendas por ação atual). 


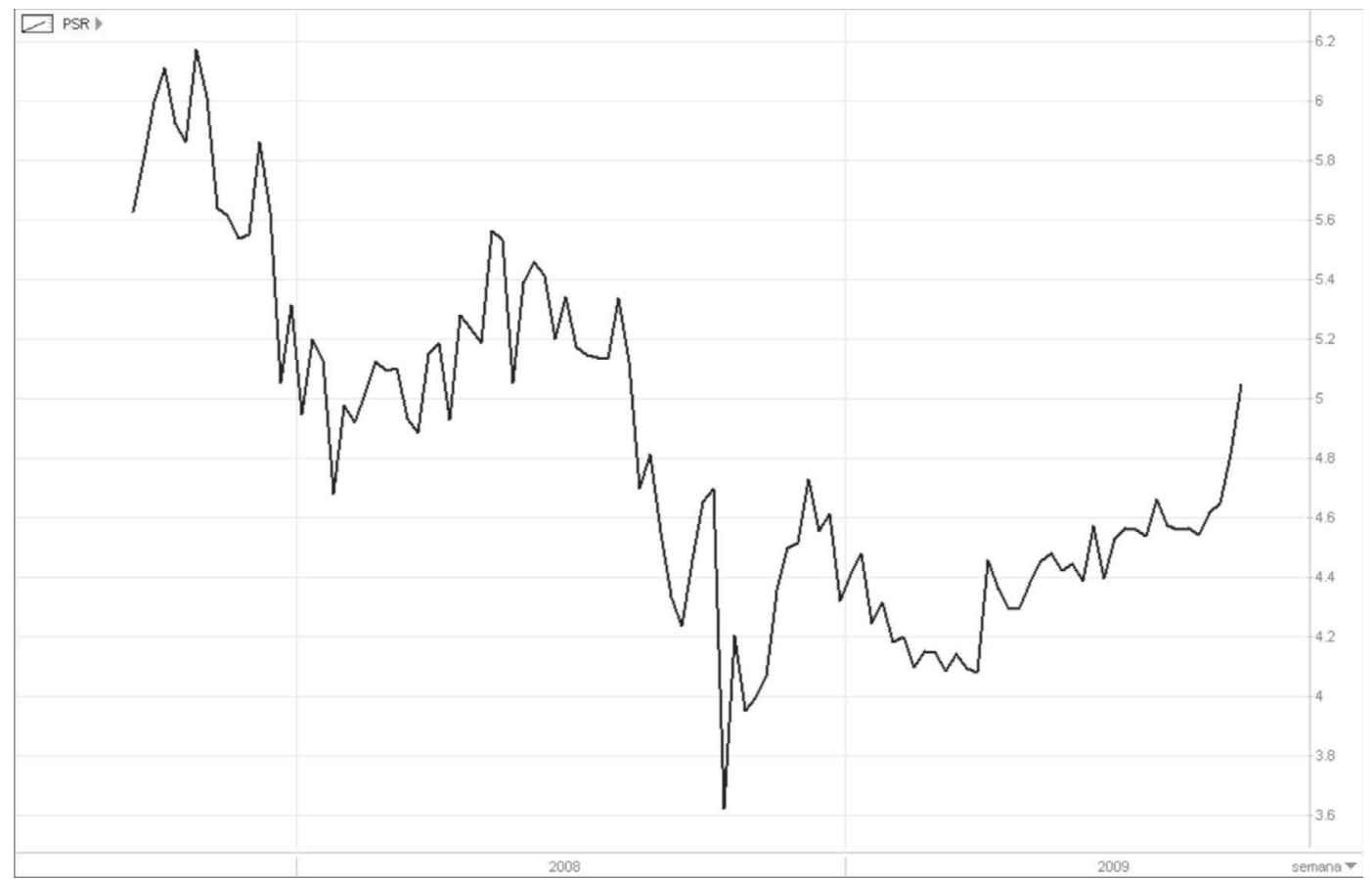

Gráfico 5: Variação do PSR das ações da Tractebel de setembro de 2007 a setembro de 2009 Fonte: Economática (2010)

A partir da avaliação relativa histórica, o preço justo da Tractebel encontra-se em uma faixa de preço entre $\mathrm{R} \$ 10,69$ e $\mathrm{R} \$ 23,37$. Com isso, pode-se concluir que a comparação dos múltiplos com seus valores históricos gera resultados mais consistentes e coerentes do que a comparação com empresas pares, o que pode ser justificado pela dificuldade em encontrar ativos semelhantes a Tractebel Energia. Não obstante, ao comparar os resultados alcançados, percebe-se que quatro dos cinco ficaram entre $\mathrm{R} \$ 19,24$ e $\mathrm{R} \$ 23,37$, o que é muito próximo do atual valor da empresa. Assim, o dividend yield não aparenta ser um parâmetro de comparação, uma vez que a empresa tem retido cada vez mais seus lucros.

\section{I.3 Avaliação pelo modelo de dividendo descontado}

A avaliação pelo modelo de dividendos descontado considera que o único fluxo de caixa de um investidor são os dividendos. Em função disso, para precificar um ativo é preciso estimar os dividendos futuros e trazê-los 
para valores presentes, o que implica em definir uma taxa de desconto e de crescimento. Para tanto, é fundamental analisar o comportamento da política de dividendos ao longo dos anos, em termos de taxas de payout (parcela do lucro distribuída sobre a forma de dividendos e juros sobre o capital próprio), de retenção (parcela que a empresa retém para investir em seu crescimento) e de crescimento. Com isso, tem-se:

Tabela 2: DPA, DIV YTY, payout, índice de retenção e retorno sobre o patrimônio próprio entre 1998 e 2008

\begin{tabular}{c|cc|c|c|c|c}
\hline ANO & \multicolumn{2}{|c|}{ DPA } & DIV YTY & $\%$ PAYOUT & \% RETENÇÃO & $\%$ ROE \\
\hline 1998 & R\$ & - & - & $23.70 \%$ & $76.30 \%$ & $0.00 \%$ \\
\hline 1999 & R\$ & - & - & $0.00 \%$ & $0.00 \%$ & $-3.30 \%$ \\
\hline 2000 & R\$ & - & - & $84.00 \%$ & $16.00 \%$ & $6.70 \%$ \\
\hline 2001 & R\$ & 0.36 & - & $30.30 \%$ & $69.70 \%$ & $19.80 \%$ \\
\hline 2002 & R\$ & 0.16 & $-55.44 \%$ & $0.00 \%$ & $0.00 \%$ & $-6.60 \%$ \\
\hline 2003 & R\$ & 0.64 & $303.27 \%$ & $130.00 \%$ & $0.00 \%$ & $19.90 \%$ \\
\hline 2004 & R\$ & 0.78 & $22.45 \%$ & $76.10 \%$ & $23.90 \%$ & $27.80 \%$ \\
\hline 2005 & R\$ & 1.37 & $74.65 \%$ & $111.00 \%$ & $0.00 \%$ & $34.30 \%$ \\
\hline 2006 & R\$ & 1.53 & $11.59 \%$ & $95.00 \%$ & $5.00 \%$ & $35.40 \%$ \\
\hline 2007 & R\$ & 1.42 & $-6.92 \%$ & $95.00 \%$ & $5.00 \%$ & $37.10 \%$ \\
\hline 2008 & R\$ & 1.86 & $30.60 \%$ & $67.85 \%$ & $32.15 \%$ & $35.20 \%$
\end{tabular}

Fonte: Adaptada do Economática (2010)

A Tabela 2 contempla um horizonte de 11 anos, de 1998 a 2008, e representa todo o histórico da organização. A partir dela, pode-se perceber que a distribuição dos lucros (DPA) começou em 2001, três anos após o surgimento da empresa, e, desde então, vem apresentando um crescimento anual médio de $22,98 \%$ ao ano. Diante disso, cabe salientar que o aumento anual (DIV YTY) tem sido muito irregular e só se estabilizou nos cinco últimos anos, razão esta que justifica a tomada desse período como base. Em relação ao payout, constata-se que, de 2004 a 2008, a empresa distribuiu em média $88,99 \%$ de seus lucros, sob a forma de dividendos e juros sobre o capital próprio. Em função disso, apenas $11,01 \%$ foi retido e reinvestido nas atividades e crescimento das operações, em média. Um último ponto a ser analisado na Tabela 2 é o $\mathrm{ROE}$, ou retorno sobre o patrimônio líquido, que relaciona o lucro ao valor patrimonial e indica os níveis de rentabilidade da empresa. Nesse sentido, nota-se que durante o período-base houve uma certa estabilidade em seus valores, que variaram entre $27,80 \%$ e $37,10 \%$, e apresentaram uma média de 33,96\%. 
A análise temporal fornece uma ideia sobre as perspectivas futuras da empresa com relação à política de dividendos e à taxa de crescimento. Nesse sentido, os teóricos estudados apontam que para efetuar projeções futuras pode-se: identificar padrões de comportamento passados ou relacionar as taxas de retenção ao retorno sobre o capital próprio. Assim, cabe destacar que não foi possível identificar um padrão claro na evolução da política de dividendos e da taxa de crescimento em função de sua alta variabilidade, $e$ por isso, a segunda alternativa se mostrou mais confiável. Portanto, ao tomar o intervalo de 2004 a 2008 como base e relacionar a taxa de retenção média (11,01\% aa) ao retorno patrimonial médio desse mesmo período (33,96\% aa), pôde-se estimar um crescimento futuro nos dividendos de 3,74\% ao ano.

A despeito do período em que se dará esse crescimento, vale ressaltar que apesar da política de dividendos entre 1998 a 2004 ter sido incomum, em função do pouco tempo de vida da organização, os dividendos tendem a apresentar um comportamento bastante estável ao longo do tempo. Esse comportamento reflete as políticas organizacionais e as preocupações da administração em manter os dividendos em níveis que possam ser sustentados, mesmo com volatilidade nos lucros. Em função disso, espera-se que o crescimento de $3,74 \%$ ao ano seja perpétuo, ou seja, não varie ao longo do tempo, independente da variação dos lucros e das taxas de inflação.

Além da identificação das taxas de crescimento, o MDD também exige a definição de uma taxa de desconto. Para tal propósito, os teóricos reconhecem diversos modelos, mas apontam o CAPM como o mais consagrado e utilizado. Por isso, essa técnica será utilizada para trazer os dividendos a valores presentes e é obtida da seguinte forma:

Tabela 3: Custo de capital próprio da Tractebel

DATA $2009-\infty$
TAXA LIVRE DE RISCO

$8.7 \%$
PRÊMIO MERCADO $2.3 \%$
COEFICIENTE BETA

0.35
CUSTO CAPITAL PRÓPRIO $9.5 \%$

Fonte: Adaptada do Economática (2010)

A partir da Tabela 3, que apresenta e detalha os componentes do CAPM, pode-se perceber inicialmente que o cálculo está relacionado ao mesmo período da taxa de crescimento, ou seja, a perpetuidade. Não obstante, notase que foi definido $8,75 \%$ ao ano como taxa livre de risco, uma vez que esse é o atual valor da taxa Selic, que por sua vez, representa a remuneração nominal do principal título da dívida pública brasileira, LFT (Letra Financeira 
do Tesouro). Pode-se constatar ainda, que foi adotado um coeficiente beta de 0,35 , referente aos últimos 60 meses, mas que se manteve constante nos últimos 48, 36 e 24 meses.

Sobre a definição do prêmio pelo risco, cabe fazer algumas considerações: antes de mais nada, seu cálculo é feito a partir da diferença entre a rentabilidade esperada da taxa livre de risco e da carteira de mercado. A rentabilidade esperada é obtida a partir da rentabilidade observada, ou histórica, que se baseia em um período de análise, que deve ser o mais longo possível. Diante disso, poder-se-ia considerar toda a série histórica da taxa Selic, que parte de 1984. No entanto, Mynbaev e Lemos (2004) sugerem que a regressão histórica deve partir de um cenário de estabilidade, visto que não se pode fazer inferências futuras a partir da análise de cenários extremos. Diante disso, e, considerando que o período entre 1984 e 1998 foi marcado por altas taxas de juros, decorrentes da inflação e do risco país, tomou-se como base os últimos dez anos, ou seja, outubro de 1999 a outubro de 2009. Nesse período, a taxa Selic apresentou uma rentabilidade anual média de $16.37 \%$, enquanto o Ibovespa se valorizou em média 18,67\% ao ano. Assim, o prêmio pelo risco dos últimos dez anos foi de $2.3 \%$ e o custo de capital próprio, calculado pelo CAPM, foi de 10,1\%. Diante dos inputs levantados, tem-se:

\begin{tabular}{|c|c|}
\hline Índice de Retenção médio (5 anos) & $11.01 \%$ \\
\hline Rentabilidade Patrimonial média (5 anos) & $33.96 \%$ \\
\hline Taxa de Crescimento (perpetuidade) & $3.74 \%$ \\
\hline Custo de Capital próprio & $9.55 \%$ \\
\hline Dividendo médio (5 anos) & $\mathrm{R} \$ 1,39$ \\
\hline Preço-alvo por Ação & $\mathrm{R} \$ 23,92$ \\
\hline
\end{tabular}

Quadro 1: Preço-alvo pelo modelo de dividendo descontado Fonte: Elaborado pelos autores

Considerando um dividendo médio de $\mathrm{R} \$ 1,39$ dos últimos cinco anos, uma taxa de crescimento perpétua sobre ele de $3,74 \%$ ao ano e uma taxa de desconto de $10,10 \%$ ao ano, o preço justo para as ações da Tractebel pelo modelo de dividendo descontado é de $\mathrm{R} \$ 23,92$. Esse valor se encontra próximo do atual valor de mercado da empresa, que é de aproximadamente $\mathrm{R} \$ 20,50$. 


\section{I.4 Avaliação pelo modelo do fluxo de caixa descontado}

O último modelo a ser utilizado é o fluxo de caixa descontado (FCD), que considera toda a complexidade macroeconômica e organizacional, e parte da premissa básica de que o valor de uma empresa depende de sua capacidade de remunerar o acionista. Essa capacidade, diferente do MDD, é obtida a partir do desconto dos fluxos de caixa livres. De forma análoga ao MDD, o FCD tem como principais inputs: os fluxos futuros, as taxas de crescimento, $e$ as de desconto e a perpetuidade. Porém, diferente dos dividendos, os fluxos de caixa apresentam variações muito grandes ao longo do tempo, visto que não são definidos por políticas organizacionais $e$ dependem de condições externas à organização. Diante disso, faz-se necessário analisar o comportamento e evolução dos fluxos nos últimos anos, estimar seus valores futuros, definir uma perpetuidade e uma taxa de desconto, para finalmente atribuir um valor à Tractebel Energia.

\section{I.4. I A análise dos fluxos de caixa passados}

A análise do comportamento dos fluxos de caixa depende inicialmente da definição de um período-base. Esse período deve contemplar um intervalo em que haja estabilidade e seja possível identificar alguma tendência ou comportamento padronizado. Assim, cabe destacar que desde seu surgimento em 1998, a Tractebel vem tendo um forte crescimento. Nos últimos dez anos, seu faturamento líquido cresceu $374 \%$, passando de $\mathrm{R} \$ 725$ milhões para $\mathrm{R} \$ 3,441$ bilhões. Contudo, expansões como essa são comuns nos primeiros anos de uma organização, mas à medida que ela se desenvolve, seu crescimento tende a se estabilizar e se manter constante. Diante disso, e considerando que os primeiros cinco anos da empresa foram bastante atípicos, será analisado o intervalo entre 2004 e 2009.

Além de definir um período-base, a análise dos fluxos de caixa passados deve contemplar também um estudo da evolução do faturamento, do lucro EBITDA, da depreciação e dos investimentos em bens de capital e capital de giro. Assim, tem-se: 
Tabela 4: Fluxo de caixa livre da Tractebel durante 2004 a 2008

\begin{tabular}{|c|c|c|c|c|c|c|c|c|c|c|c|c|c|}
\hline DATA & VENDAS & \multicolumn{2}{|c|}{ UCRO EBIT } & \multicolumn{2}{|c|}{$\begin{array}{c}\text { LUCRO IIQ } \\
\text { (SEM DESP FINAN) }\end{array}$} & \multicolumn{2}{|c|}{ DEPRECIAÇÃO } & \multicolumn{2}{|c|}{ CAPEX } & \multicolumn{2}{|c|}{$\begin{array}{l}\text { INVESTIM } \\
\text { CAP GIRO }\end{array}$} & \multicolumn{2}{|c|}{$\begin{array}{l}\text { FLX DE CX LIV } \\
\text { DA EMPRESA }\end{array}$} \\
\hline $12 / 31 / 2004$ & $\mathrm{R} \$ \mathrm{3}$, & $\mathrm{R} \$$ & & $\mathrm{RS}$ & 852.83 & $\mathrm{R} \$$ & & & 47.56 & $\mathrm{R} \$$ & $(20.51)$ & $\mathrm{R} \$$ & $1,111.67$ \\
\hline $12 / 31 / 2005$ & $R \$ 3,054.51$ & $\mathrm{R} \$$ & 1.4 & $R$ & 932.77 & $\mathrm{RS}$ & & & 51.60 & 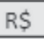 & 22.70 & $\mathrm{RS}$ & .90 \\
\hline $12 / 31 / 2006$ & $\mathrm{R} \$ 3,081.85$ & $\mathrm{RS}$ & $1,579.52$ & $\mathrm{RS}$ & 042.48 & $\mathrm{RS}$ & 03 & $\mathrm{R}$ & 78.64 & $R \$$ & $(80.35)$ & $\mathrm{RS}$ & 9.22 \\
\hline $12 / 31 / 2007$ & $\mathrm{R} \$ 3,318.81$ & $\mathrm{RS}$ & $1,775.53$ & $\mathrm{RS}$ & & $\mathrm{RS}$ & & $\mathrm{R} \$$ & 768.30 & & $(24.63)$ & $\mathrm{RS}$ & \\
\hline $12 / 31 / 2008$ & $\mathrm{R} \$ 3,543.14$ & $\mathrm{RS}$ & $1,970.55$ & $\mathrm{RS}$ & $1,300.56$ & $\mathrm{RS}$ & 274.29 & $\mathrm{RS}$ & $1,564.88$ & $\mathrm{RS}$ & 103.47 & $\mathrm{RS}$ & $(93.50)$ \\
\hline
\end{tabular}

Fonte: Adaptada do Economática (2010)

O fluxo de caixa livre da empresa no período de 2004 a 2008, assim como parte de seus componentes, foi bastante irregular, e, em função disso, não foi possível identificar um comportamento padronizado. Ao considerar o intervalo entre 2004 e 2006, percebe-se que há certa estabilidade, com um breve aumento, uma vez que os valores oscilaram apenas entre $\mathrm{R} \$ 1.111,67$ e R $\$ 1.289,22$ bilhões. No entanto, esse comportamento não se manteve nos anos seguintes, em que houve um fluxo positivo de $\mathrm{R} \$ 685,39$, seguido por um fluxo negativo de $\mathrm{R} \$ 93,50$ bilhões. A principal razão da diferença entre esses dois momentos está no capex (investimentos em bens de capital), que aumentou consideravelmente após um período de estabilidade. Em relação aos outros componentes, verifica-se que a depreciação se manteve constante, e o capital de giro, apesar da sua oscilação, teve pouca relevância na determinação do fluxo de caixa livre da empresa, com exceção do último ano.

\subsection{4 A construção dos fluxos de caixa}

A construção dos fluxos de caixa futuros pode se dar de três formas: através da utilização da taxa de crescimento histórico; da obtenção de estimativas de fontes mais informadas; e/ou da identificação de quanto uma empresa reinveste no crescimento futuro e qual a qualidade desse reinvestimento. Diante dessas alternativas, Damodaran (2007) sugere que a última é a mais confiável e a que possui o menor caráter subjetivo, pois considera todos os fundamentos da empresa. Porém, ao se realizar um back testing, relacionando os montantes investidos e suas taxas de retorno, percebeu-se que os resultados alcançados não corresponderam ao crescimento auferido. Além disso, o modelo fundamental de crescimento depende da estimativa dos investimentos futuros da empresa. Tendo em vista a falta de uma tendência clara no capex e no capital de giro, há uma dificuldade adicional neste processo. A partir disso, e considerando a 
impossibilidade de se obter estimativas de fontes mais informadas, os fluxos de caixa futuros serão construídos através da taxa de crescimento histórico da empresa.

De forma análoga à análise histórica, a projeção dos fluxos de caixa futuros também deve partir de um período-base. Nesse sentido, Damodaran (1997) aponta que o horizonte de projeção deve contemplar um intervalo entre cinco e dez anos, dependendo do grau de certeza e de conhecimento que se tem do ativo. Portanto, considerando o histórico analisado, parte-se do pressuposto de que os próximos cinco anos irão refletir o desempenho ajustado dos últimos cinco. Para tanto, é necessário identificar o comportamento e a evolução dos itens determinantes do fluxo de caixa livre: faturamento líquido, lucro EBITDA, depreciação e investimentos em bens de capital e capital de giro.

A análise do período de 2004 a 2008 indica que o crescimento médio do faturamento da Tractebel nos últimos cinco anos foi de $2,9 \%$ ao ano. Assim, tomando-se como base os recentes projetos da empresa e não desconsiderando a alta volatilidade histórica, espera-se que o crescimento entre 2004 e 2008 se reflita no período de 2009 a 2013 como um todo. Em relação à margem EBITDA, constatou-se uma melhora contínua e estável, atingindo 63,64\% em 2008. Diante disso, espera-se que essa margem permaneça constante nos anos seguintes. Sobre a depreciação, nota-se que houve pouca variação em relação ao imobilizado total, mantendo-se em média $6,78 \%$ ao ano durante todo o período. Assim, espera-se que a relação entre depreciação e imobilizado para os próximos anos se mantenha nesse patamar. Com isso, também se pode supor que a razão entre o capex e o imobilizado se enquadre nessa mesma lógica, a qual corresponderia a $209 \%$ ao ano. Por fim, sobre os investimentos em capital de giro, a análise histórica do giro médio de estoques, do período médio de recebimento e de pagamento, indicou que há um grande estabilidade nos dados. Nesse sentido, pode-se esperar que a média dos valores desses itens se mantenha constante durante o período de projeção. Portanto, a partir do faturamento projetado, o capital de giro deverá variar de um desinvestimento de $\mathrm{R} \$ 12,28$ milhões a um investimento de $\mathrm{R} \$ 7,20$ milhões. 
Tabela 5: Fluxo de caixa livre da Tractebel projetado para o período de 2009 a 2013

\begin{tabular}{|c|c|c|c|c|c|c|c|c|c|c|c|c|c|}
\hline DATA & VENDAS & \multicolumn{2}{|c|}{ UCRO EBIT } & \multicolumn{2}{|c|}{$\begin{array}{c}\text { LUCRO LIQ } \\
\text { (SEM DESP FINAN) }\end{array}$} & \multicolumn{2}{|c|}{ DEPRECIAÇÃO } & \multicolumn{2}{|r|}{ CAPEX } & \multicolumn{2}{|c|}{$\begin{array}{l}\text { INVESTIM } \\
\text { CAP GIRO }\end{array}$} & \multicolumn{2}{|c|}{$\begin{array}{l}\text { FLX DE CX LIV } \\
\text { DA EMPRESA }\end{array}$} \\
\hline $12 / 31 / 2009$ & $R \$ 3,646.95$ & $\mathrm{R} \$$ & $1,848.74$ & $\mathrm{RS}$ & $1,220.17$ & $R$ & & 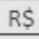 & & $\mathrm{RS}$ & (12.28) & $\mathrm{R} \$$ & 727.31 \\
\hline $12 / 31 / 2010$ & $\mathrm{R} \$ 3,752.72$ & $\mathrm{R} \$$ & $1,880.08$ & $\mathrm{RS}$ & $1,240.85$ & $\mathrm{RS}$ & 499.14 & $\mathrm{RS}$ & $1,043.21$ & $R S$ & 5.81 & $\mathrm{RS}$ & 690.98 \\
\hline $12 / 31 / 2011$ & $\mathrm{R} \$ 3,861.54$ & $\mathrm{RS}$ & $1,912.08$ & $\mathrm{RS}$ & $1,261.97$ & $R \$$ & 536.14 & $\mathrm{RS}$ & $1,120.53$ & $\mathrm{RS}$ & 6.80 & $\mathrm{RS}$ & 70.78 \\
\hline $12 / 31 / 2012$ & $\mathrm{R} \$ 3,973.53$ & $\mathrm{R} \$$ & $1,943.34$ & $R \$$ & $1,282.60$ & $R \$$ & 575.88 & $\mathrm{R} \$$ & $1,203.59$ & i\$ & 7.00 & $\mathrm{RS}$ & 647.90 \\
\hline $12 / 31 / 2013$ & $R \$ 4,088.76$ & $\mathrm{R} \$$ & $1,973.71$ & $\mathrm{RS}$ & $1,302.65$ & $\mathrm{RS}$ & 618.56 & $\mathrm{RS}$ & $1,292.80$ & $\mathrm{RS}$ & 7.20 & $\mathrm{R} \$$ & 621.22 \\
\hline
\end{tabular}

Fonte: Adaptada do Economática (2010)

Diferente do fluxo de caixa de 2004 a 2008, o fluxo projetado se mostra bastante regular, uma vez que se utiliza valores predefinidos e constantes. Verifica-se que há uma tendência clara e progressiva em todos os itens. Dentre eles, o capex é o que apresenta maior impacto e relevância na determinação do fluxo final. Como esse item é definido a partir de sua razão com a depreciação, à medida que ela aumenta, seu valor também aumenta e como consequência, o fluxo de caixa diminui. Por outro lado, o investimento em capital de giro é o menos expressivo, sendo praticamente nulo, quando comparado aos demais itens. Portanto, o fluxo de caixa livre da Tractebel Energia deverá variar de $\mathrm{R} \$$ 727,31 em 2009 para $\mathrm{R}$ \$ 621,22 milhões em 2010.

\section{I.4.3 O valor residual ou da perpetuidade}

Além de projetar os fluxos de caixa para o período-base, é necessário definir o valor residual (ou da perpetuidade), ou seja, o valor que esses fluxos deverão crescer durante a eternidade. Para tal finalidade, Cornell (apud CERBASI, 2003) destaca que nenhuma empresa pode crescer indefinidamente a uma taxa superior ao PIB (Produto Interno Bruto) nacional. Nesse sentido, e tomando como base que o crescimento da economia depende do fornecimento de energia, estima-se que após os cinco anos de projeção a Tractebel deverá crescer no mesmo ritmo que o país. No entanto, essa dedução traz uma nova dificuldade, que é estimar o crescimento perpétuo do PIB.

Para resolver essa situação, tomou-se como base as projeções do relatório Focus, que é elaborado e divulgado semanalmente pelo Banco Central. O relatório reúne as opiniões das principais instituições financeiras e reflete a expectativa do mercado em relação à projeção de variáveis econômicas, como o PIB. Nesse sentido, o relatório do dia 12 de outubro de 2009 trazia uma expectativa de crescimento da economia de $4,0 \%$ para 2010 . Com isso, e levando em consideração a enorme dificuldade em fazer projeções para horizontes mais extensos, será assumida essa taxa como a perpetuidade. 
Assim, deduz-se que o último fluxo de caixa projetado irá crescer a uma taxa de $4 \%$ ao ano indefinidamente.

\subsubsection{A taxa de desconto}

O último elemento a ser definido no FCD é a taxa de desconto que deverá trazer os fluxos de caixa a valores presentes. Para tanto, deve-se utilizar o custo médio ponderado de capital (WACC), que representa uma ponderação do custo de capital próprio e de terceiros. Diante disso, faz-se necessário definir inicialmente o custo de capital de terceiro e a estrutura de capital da empresa. Para as duas finalidades, deve-se partir de uma análise histórica do período-base de análise. Assim, tem-se:

Tabela 6: Estrutura de capital e custo de capital de terceiros da Tractebel

\begin{tabular}{c|c|c|c|c}
\multirow{2}{*}{ DATA } & \multicolumn{2}{|c|}{ DIV BRT / (DIV BRT + VLR DE MERC) \% } & \multicolumn{2}{c}{ CUS CAP TER \% (REAL) } \\
\cline { 2 - 5 } & TRACTEBEL & SETOR & TRACTEBEL & SETOR \\
\hline $31 / 12 / 2004$ & $25.6 \%$ & $51,4 \%$ & $3.0 \%$ & $13.80 \%$ \\
\hline $31 / 12 / 2005$ & $13.4 \%$ & $38.30 \%$ & $6.1 \%$ & $15.90 \%$ \\
\hline $31 / 12 / 2006$ & $9.8 \%$ & $30.70 \%$ & $13.7 \%$ & $17.50 \%$ \\
\hline $31 / 12 / 2007$ & $11.5 \%$ & $23.70 \%$ & $13.4 \%$ & $14.60 \%$ \\
\hline $31 / 12 / 2008$ & $19.7 \%$ & $35.80 \%$ & $17.7 \%$ & $12.80 \%$ \\
\hline $2009-\infty$ & $16.0 \%$ & $25.7 \%$ & $10.8 \%$ & $14.9 \%$
\end{tabular}

Fonte: Adaptada do Economática (2010)

A partir da Tabela 6, percebe-se que, de 2004 a 2008, a participação do capital de terceiro nas fontes de financiamento tem se mantido relativamente estável, oscilando entre 9,8\% e 25,6\%. Com isso, não foi possível identificar um padrão de comportamento crescente, mas sim constante, uma vez que houve uma redução dos níveis em um primeiro momento, seguido por um aumento. Nesse sentido, pode-se esperar que a estrutura de capital futura da empresa mantenha-se na média dos últimos cinco anos, ou seja, $16 \%$.

Em relação ao custo de capital de terceiro, cabe destacar que assim como toda a análise do FCD, os valores são apresentados em termos reais e não incorporam a inflação. Com isso, também é possível perceber uma certa estabilidade nos dados, que variaram entre 3\% e 17,7\% e comportaram-se de forma semelhante ao setor. Assim, pode-se esperar que o custo de capital de terceiro médio durante o período-base $(10,8 \%)$ mantenha-se constante e reflita-se no futuro. Além disso, é preciso definir também o custo de capital próprio, a partir do CAPM, cujos componentes são apresentados: 
Tabela 7: Custo médio ponderado de capital da Tractebel

\begin{tabular}{c|c|c|c|c|c|c|} 
DATA & $\begin{array}{c}\text { TAXA LIVRE } \\
\text { DE RISCO }\end{array}$ & $\begin{array}{c}\text { PRÊMIO } \\
\text { MERCADO }\end{array}$ & $\begin{array}{c}\text { COEFICIENTE } \\
\text { BETA }\end{array}$ & $\begin{array}{c}\text { CUSTO REAL } \\
\text { CAPITAL TER }\end{array}$ & $\begin{array}{c}\text { CUSTO CAPITAL } \\
\text { PRÓPPIO }\end{array}$ & WACC REAL \\
\hline $2009 .=$ & $6.4 \%$ & $2.3 \%$ & 0.35 & $7.2 \%$ & $7.1 \%$ & $7.2 \%$ \\
\hline
\end{tabular}

Fonte: Adaptado do Economática (2010)

O cálculo do CAPM partiu das mesmas premissas definidas no custo de capital do MDD. A única diferença está no fato da utilização de valores reais, ao invés de nominais. Nesse caso, a taxa livre de risco é de $6,4 \%$ e não se baseia na taxa Selic, que remunera a Letra Financeira do Tesouro, mas sim na rentabilidade da Nota do Tesouro Nacional Classe $B$, com vencimento em 2045. Esse título também é considerado livre de risco, pois é garantido pelo Tesouro Nacional e apresenta uma remuneração pré-fixada de 6,4\% ao ano mais uma parcela indexada ao IPCA (Índice de Preços ao Consumidor Amplo), que é o índice de inflação oficial do governo. Assim, encontrou-se um custo real de $7,1 \%$ ao ano.

A partir das diversas fontes de financiamento e da estrutura de capital projetada na empresa, deve-se ainda levar em consideração a alíquota de imposto de renda, que funciona como um subsídio quando se utiliza capital de terceiros. Nesse sentido, partindo de uma alíquota de $34 \%$ ao ano, definida anteriormente, chega-se a um custo médio ponderado de capital real de 7,2\% ao ano.

\section{I.4.5 Preço-alvo do fluxo de caixa descontado}

Tendo em vista a definição do fluxo de caixa dos próximos cinco anos e da perpetuidade e da taxa de desconto que deverá trazer tais fluxos a valores presentes, deve-se proceder da seguinte forma para se chegar a um preço teórico da Tractebel Energia: 


\begin{tabular}{|l|l|}
\hline (+) Valor presente do fluxo de caixa nos cinco primeiros anos & $\mathrm{R} \$ 2.332,45$ \\
\hline (+) Valor presente do fluxo de caixa na perpetuidade & $\mathrm{R} \$ 14.928,04$ \\
\hline (=) Valor presente do fluxo de caixa total & $\mathrm{R} \$ 17.260,49$ \\
\hline (+) Investimento em empresas não coligadas & $\mathrm{R} \$ 30,93$ \\
\hline (=) Valor da empresa & $\mathrm{R} \$ 17.291,42$ \\
\hline (-) Dívida total & $\mathrm{R} \$ 3.082,35$ \\
\hline (+) Caixa atual & $\mathrm{R} \$ 428,48$ \\
\hline (=) Valor de mercado-alvo & $\mathrm{R} \$ 14.637,55$ \\
\hline (/) Quantidade de ações (milhões) & 652.74 \\
\hline (=) Preço alvo da ação & $\mathrm{R} \$ 22,42$ \\
\hline
\end{tabular}

Quadro 2: Preço-alvo pelo modelo de fluxo de caixa descontado Fonte: Elaborado pelos autores

A partir dos dados levantados, deve-se inicialmente apresentar os fluxos de caixa em valores presentes. Assim, ao se descontar o caixa dos cinco primeiros anos e da perpetuidade encontra-se $\mathrm{R} \$ 2.332,45$ e $\mathrm{R} \$ 14.928,04$ bilhões, respectivamente, o que representa um total de $\mathrm{R} \$ 17.260,49$ bilhões. Além disso, deve-se incluir os investimentos em empresas coligadas, já que tais investimentos não estão incluídos nos ativos operacionais e não provocam impacto nos fluxos descontados. Com isso, deve-se somar $\mathrm{R} \$ 30,93$ milhões para se chegar a um novo total de $\mathrm{R} \$ 17.291,42$ bilhões. Esse valor envolve tanto recursos próprios quanto de terceiros, e, por isso, para se chegar ao valor dos acionistas, deve-se diminuir a dívida bruta, que representa $\mathrm{R} \$ 3.082,35$ bilhões e somar o caixa, que, da mesma forma que os investimentos, não colabora para a geração de caixa da empresa. Diante disso, chega-se ao valor de mercado-alvo da Tractebel, que é de $\mathrm{R} \$ 14.637,55$ bilhões, que deve ser dividido pela quantidade total de ações da empresa, que é de 652.74 milhões, para se chegar ao preço-alvo por ação, que é de $\mathrm{R} \$ 22,42$.

\subsection{Comparação de Resultados}

Para se atribuir um valor justo às ações da Tractebel Energia foram utilizados os principais modelos de precificação de ativos. Cada um desses modelos possui vantagens e desvantagens, aplicações e limitações. Em função disso, os resultados obtidos inicialmente evidenciaram a necessidade de se 
efetuar ajustes. Há de se considerar também a discrepância entre os modelos. Portanto os resultados finais devem ser confrontados entre si e reajustados, para que seja possível atribuir um valor preciso à empresa objeto. Estes resultados foram:

\begin{tabular}{|l|l|}
\hline Valor contábil & $\mathrm{R} \$ 23,37$ \\
\hline Valor relativo PER & $\mathrm{R} \$ 19,24$ \\
\hline Valor relativo P/EBITDA & $\mathrm{R} \$ 20,95$ \\
\hline Valor relativo P/VPA & $\mathrm{R} \$ 23,37$ \\
\hline Valor relativo DIV YLD & $\mathrm{R} \$ 10,69$ \\
\hline Valor relativo PSR & $\mathrm{R} \$ 21,83$ \\
\hline Valor dividendo descontado (MDD) & $\mathrm{R} \$ 23,92$ \\
\hline Valor fluxo de caixa descontado (FCD) & $\mathrm{R} \$ 22,42$ \\
\hline
\end{tabular}

Quadro 3: Resultados obtidos na aplicação dos principais modelos de precificação Fonte: Elaborado pelos autores

A partir dos modelos aplicados, nota-se que os valores finais ficaram em uma faixa de preço entre $R \$ 19,24$ e $R \$ 23,92$. Percebe-se que de todos os resultados, apenas o valor relativo PER se encontra isolado e em função disso, não deve ser considerado. Assim, partindo do intervalo entre R $\$ 20,95$ e $\mathrm{R} \$ 23,92$, encontrou-se um preço médio de $\mathrm{R} \$ 22,49$ e um desvio padrão de $\mathrm{R} \$ 1,18$. Portanto, o atual preço justo das ações da Tractebel Energia é de $\mathrm{R} \$ 22,49$, no entanto, em função da amplitude dos resultados, deve-se admitir uma faixa de precificação entre $R \$ 21,31$ e $R \$ 23,67$, conforme a figura 1:

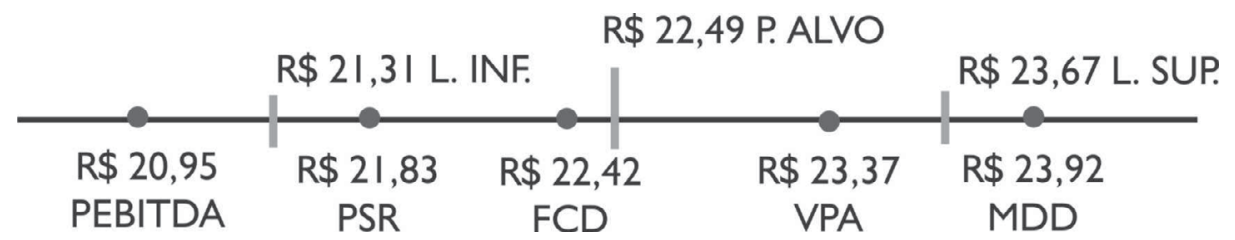

Figura 1: Preço-alvo da Tractebel Energia

Fonte: Elaborada pelos autores 
A despeito desse resultado, vale salientar que se trata de uma estimativa, e como tal, há um aspecto subjetivo e incertezas em relação ao cenário futuro. Nesse sentido, os valores obtidos refletiram as atuais expectativas, e para que tenham relevância em períodos futuros, deve haver a incorporação de novas informações e revisão de suas premissas. Por fim, percebe-se que o valoralvo da empresa se encontra muito próximo do preço obtido pelo fluxo de caixa descontado, o qual foi descrito na fundamentação teórica como o modelo de maior aceitação e utilização.

\section{Considerações Finais}

O presente estudo teve como objetivo definir o atual valor justo da empresa Tractebel, a partir dos principais modelos de precificação de ativos de forma a fornecer subsídio para a tomada de decisão de investidores e da Tractebel, no que se refere à compra ou venda de suas ações. Para tal finalidade, foi necessário descrever e analisar os principais métodos de avaliação de empresas, relacionando suas aplicações e limitações. Nesse sentido, o primeiro modelo estudado foi a avaliação contábil que se baseia no valor extraído do balanço patrimonial. Essa técnica apesar de simples e intuitiva, não permite avaliar a capacidade da organização em gerar resultados, e por isso, sua aplicação efetiva se limita a empresas com baixo goodwill. O segundo modelo foi a avaliação relativa, que parte da ideia de que empresas similares devem ser cotadas a preços similares. Esse método envolve a utilização de índices de mercado e pode ser aplicado em qualquer ativo. Porém, sua maior dificuldade é determinar empresas comparáveis, em termos de risco, fluxo de caixa e potencial de crescimento.

Outro modelo analisado foi o dividendo descontado, que considera que o preço justo de uma empresa depende de sua capacidade de remunerar os acionistas, o que se dá através dos dividendos. O MDD apresenta como maior limitação o fato das empresas nem sempre distribuírem todo o lucro disponível. Em relação à aplicação, essa técnica traz resultados consistentes quando empregada em empresas que possuem uma política de dividendos estável e distribuem todo o fluxo de caixa disponível. Por fim, o último modelo foi o fluxo de caixa descontado, que desconta o fluxo de caixa livre ao invés dos dividendos, que é o principal método de avaliação, mas apresenta certas restrições quando é utilizado em empresas com dificuldade financeira ou que 
possuem um fluxo de caixa muito volátil. Por outro lado, o FCD pode ser empregado sempre que for possível estimar os fluxos de caixa futuros.

A etapa seguinte à descrição foi a implementação de cada um dos modelos de avaliação, o que envolveu a estimativa de suas variáveis. A avaliação contábil dependeu tanto da análise patrimonial, quanto da sua evolução histórica, e chegou a um preço de $\mathrm{R} \$ 23,37$ por ação. Sobre a avaliação relativa, foi necessário inicialmente definir os índices e empresas comparáveis. No entanto, percebeu-se que o setor não refletia a realidade organizacional e por isso os índices da empresa foram comparados com suas médias históricas. Assim, foram obtidos os seguintes valores, de acordo com cada múltiplo: $\mathrm{R} \$ 19,24 \mathrm{PER}, \mathrm{R} \$ 20,95$ P/EBITDA, R $\$$ 23,37 P/VPA, $\mathrm{R} \$ 10,69 \mathrm{DIV}$ YLD e $\mathrm{R} \$ 21,83$ PSR.

Para o dividendo descontado, relacionou-se a parcela média do lucro retido pela empresa nos últimos cinco anos ao retorno sobre o capital próprio médio desse mesmo período para se estimar a taxa de crescimento nos dividendos. Com isso, tomou-se como base os dividendos médios dos últimos cinco anos e assumiu-se uma perpetuidade no crescimento, haja vista que a política de distribuição de lucros de uma empresa tende a se manter constante. Por fim, definiu-se o custo de capital próprio pelo método CAPM, o qual foi utilizado para trazer os dividendos futuros a valores presentes e se chegar a um valor de $\mathrm{R} \$ 21,91$ por ação.

Em relação ao fluxo de caixa descontado, fez-se necessário analisar a evolução dos fluxos da empresa e o comportamento de seus itens nos últimos cinco anos. Esse período foi tomado como base para projeção dos fluxos para os próximos cinco anos. Após esse período, assumiu-se um crescimento perpétuo equivalente ao PIB. Sobre a taxa de desconto, utilizou-se o custo médio ponderado de capital real, o qual trouxe os fluxos a valores presentes. Por último, o fluxo presente foi somado à diferença entre os ativos não operacionais e à dívida bruta da empresa, chegando a um valor de $\mathrm{R} \$ 22,42$ por ação.

Por fim, para atribuir um valor à Tractebel Energia foi necessário comparar os resultados obtidos e efetuar ajustes finais. Assim, ao confrontar os resultados dos modelos, pôde-se perceber que havia certa coerência, uma vez que seus valores encontravam-se em uma faixa entre $R \$ 19,24$ e $R \$ 23,92$. Porém, foi necessário eliminar os dados mais discrepantes, o que gerou um valor entre $R \$ 20,95$ a $R \$ 23,92$. A partir desse intervalo, foi calculada a média aritmética e o desvio padrão para se chegar ao resultado final, que foi 
$R \$ 22,49$, e inclui uma faixa entre $R \$ 21,31$ e $R \$ 23,67$, em função das incertezas nas estimativas.

\section{Just value of the Tactebel Energy: an valuation from the main models of pricing asset}

\section{Abstract}

This study aimed to determine the current fair value of Tractebel Energia, from the main asset pricing models. The company was taken as the object due to its stable growth and the ease of obtaining data, since it is located in the city of Florianopolis. Nevertheless, the volatility in its shares has been priced aroused interest. Therefore, this study intended to provide subsidy for the decision making of investors regarding the purchase or sale of company stock. For this, the theoretical treat on the concept of asset valuation and the main models available, emphasizing their applications and limitations, which are: assessment book on, discounted dividend model and discounted cash flow. Regarding the methodological aspect, the research fits into exploratory, descriptive, highly quantitative field study and case. Moreover, it was made use of desk research, literature, interview and program Economática. Thus, the analysis of data initially sought to raise the assumptions demanded by each of the models surveyed and apply them. The results were then compared and adjusted so that there is consistency. He was later adopted an arithmetic mean to assign a fair value to the company. From this average was defined as an acceptance range, depending on the variability of results and uncertainty in the estimates.

Key-words: Valuation. Discounted dividend. Discounted cash flow.

\section{Referências}

CAVALCANTE, Francisco; MISUMI, Jorge Yoshio; RUDGE, Luiz Fernando. Mercado de Capitais: o que é, como funciona. São Paulo: Campus, 2005. 
CERBASI, Gustavo Petrasunas. Metodologias para determinação do valor de empresas: uma aplicação no setor de geração de energia hidrelétrica. Dissertação (Mestrado em Administração) - Departamento de Administração. Universidade de São Paulo. São Paulo, 2003.

COPELAND, Tom; KOLLER, Tim; MURRIN, Jack. Avaliação de empresas "Valuation": calculando e gerenciando o valor das empresas. São Paulo: Pearson Education, 2002.

CRUZ, Anderson J. Metodologia para determinação do valor de empresas de biocombustíveis no Brasil. Dissertação (Mestrado em Administração) - Departamento de Administração. Universidade de São Paulo. São Paulo, 2007.

DAMODARAN, Aswalth. Avaliação de investimentos: ferramentas e técnicas para a determinação do valor de qualquer ativo. Rio de Janeiro: Qualitymark, 1997.

. Aswalth. A face oculta da avaliação: avaliação de empresas da velha tecnologia, da nova tecnologia e da nova economia. São Paulo: Makron Books, 2002.

. Aswalth. Avaliações de empresas. São Paulo: Prentice Hall, 2007.

ECONOMÁTICA. Banco de dados. Disponível em:

<http://www.economatica.com.br/>. Acesso em: 21 jun. de 2009.

FALCINI, Primo. Avaliação econômica de empresas: técnica e prática. São Paulo: Atlas, 1995.

MARTINS, Eliseu. Avaliação de empresa: da mensuração contábil à econômica. São Paulo: Atlas, 2001.

MYNBAEV, Kairat T.; LEMOS, Alan. Manual de Econometria. Rio de Janeiro: Editora FGV, 2004.

NEIVA, Raimundo Alelaf. Valor de mercado da empresa. São Paulo: Atlas, 1999. 
NOGUEIRA, Alexandre de Araújo. Metodologias para determinação do valor das empresas: uma aplicação no setor têxtil. Dissertação (Mestrado em Administração) - Departamento de Administração. Universidade de São Paulo. São Paulo, 1999.

PACHECO, André Augusto S. Avaliação de empresas: uma pesquisa sobre as metodologias e suas aplicações. Monografia (Graduação em Administração) - Departamento de Administração, Universidade de São Paulo, São Paulo, 2004.

PINHEIRO, Juliano Lima. Mercado de capitais: fundamentos e técnicas. 4. ed. São Paulo: Atlas, 2008.

ROSS, Stephen A.; WESTERFIELD, Randolph W.; JAFFE, Jeffrey F. Administração financeira: corporate finance. São Paulo: Atlas, 2008.

TRACTEBEL. A companhia. Disponível em:

$<$ http://www.tractebelenergia.com.br/>. Acesso em: 15 set. 2009. 